\title{
Evaluation of Blood Sugar Level in Children Between Age Group of 1- 6 Years: A Cross Sectional Study
}

\author{
Niharika Kotian, Ganesh Jeevanandan*and EMG Subramanian \\ ${ }^{1}$ Saveetha Dental College and Hospitals Saveetha Institute of Medical and \\ Technical Sciences Saveetha University Chennai-77, India \\ ${ }^{*}$ Department of Pedodontics Saveetha Dental College and Hospitals Saveetha Institute \\ of Medical and Technical Sciences Saveetha University Chennai-77, India \\ Corresponding author email: ganesh.sdc@saveetha.com
}

\begin{abstract}
Diabetes is a metabolic disorder which is characterised by high blood sugar level which results from defect in action of insulin. Diabetes is considered as the third most common disease in children as well as adolescents. It is observed that Type 1 diabetes mellitus is more common in children below 10 years of age whereas Type 2 Diabetes Mellitus is observed more in children between 10-17 years of age. This study was done to assess levels of Random blood sugar level in children with early childhood caries. Data collection from patient management software. 86 children were included in the study whose blood sugar level was compared to the normal range of blood sugar level in children. (80-140mg/dl) The children were divided into three groups- below normal range, normal range and above normal range. There was no statistically significant difference between the three groups $(\mathrm{p}>0.05)$. Out of eighty-six children, twelve children and blood sugar level below the normal range, seventy-three children had blood sugar levels within the normal range and one child had blood sugar level above normal range. There is no significant correlation between random blood sugar level and dental caries in 1-6 years old children. It is recommended that in future more research should be performed with a larger sample size in order to establish better clarification with respect to the topic.
\end{abstract}

KEY WORDS: RANDOM BLOOD SUGAR LEVEL, EARLY CHILDHOOD CARIES, DIABETES, CHILDREN.

\section{INTRODUCTION}

Diabetes is a metabolic disorder which is characterised by high blood sugar level which results from defect in action of insulin. Diabetes is considered as the third most common disease in children as well as adolescents. It is observed that Type 1 diabetes mellitus is more common in children below 10 years of age whereas Type 2 Diabetes Mellitus is observed more in children between 10-17 years of age. Diagnosis of diabetic condition is done by assessment of the fasting blood glucose level. If the fasting blood glucose level exceeds $126 \mathrm{mg} / \mathrm{dl}$ the child is considered to be hyperglycemic (National Diabetes Education Program, 2001; Association

Biosc Biotech Res Comm P-ISSN: 0974-6455 E-ISSN: 2321-4007

\section{crossef}

Identifiers and Pagination

Year: 2021 Vol: 14 No (10) Special Issue

Pages: 07-11

This is an open access article under Creative

Commons License Attribn 4.0 Intl (CC-BY).

DOI: $h t t p: / / d x . d o i . o r g / 10.21786 / b b r c / 14.10 .2$ et al., 2011; Ekoé and Zimmet, 2012; Pachoński et al., 2020; Mizia et al., 2021).

Few epidemiological studies correlating prevalence of dental caries with diabetes mellitus have derived contradictory results. According to Wegner et al., the frequency of caries in diabetic children is higher than those without the metabolic disorder. Early childhood caries (ECC) is a health condition developing globally. It can begin early in life and the condition tends to get severe if it goes untreated. It affects the quality of life of the child as the child may have severe issues like inability to chew, speech defects and unesthetic appearance (Wegner, 1971; Lin et al., 1999; Moore et al., 2001; Twetman et al., 2002; Somasundaram et al., 2015; Govindaraju et al., 2017; Ravikumar et al., 2017; Jeevanandan and Govindaraju, 2018; Panchal et al., 2019; Abdelseed, 2021).

Diet and feeding practices also play an important role in acquisition of the infection and development of caries. Previously our team has a rich experience in working on various research projects across multiple disciplines (Govindaraju et al., 2017a; Jeevanandan, 2017; Mahesh,
Article Information

Received: 05 $5^{\text {th }}$ Aug 2021

Accepted after revision: $15^{\text {th }}$ Oct 2021 
2018; Gheena and Ezhilarasan, 2019; Ke et al., 2019; Malli Sureshbabu et al., 2019; Mehta et al., 2019; Samuel et al., 2019; Sharma et al., 2019; Varghese et al., 2019; Venu et al., 2019; Vignesh et al., 2019; Jain et al., 2019; Jose et al., 2020; Krishnaswamy et al., 2020; Muthukrishnan et al., 2020; Samuel et al., 2020; Sathish and Karthick, 2020). Now the growing trend in this area motivated us to pursue this project.

There is no literature focussing on the correlation between blood sugar level and early childhood caries. The purpose of this study is to assess if the random blood sugar level of the child has any correlation with early childhood caries.

\section{MATERIALAND METHODS}

The study was based on a university setting. The ethical approval was given by the Institutional Scientific Review Board, Saveetha Dental College and Hospitals. There were three reviewers involved in the study. One of the reviewers was an external reviewer. The data for the study was collected from patient management software. Inclusion criteria: Child with early childhood caries (based on DMFT score), Age group: 1-6 years old. A total of eightysix children were included in the study from whom consent was taken prior the study. The procedure was explained to the parents or the guardian. The included children were sent for a blood test. The data was segregated and tabulated. The parameters assessed were, age and blood sugar level of children. Grouping of parameters was done on the excel sheet. The data was then copied into the SPSS 2.0 software and statistical analysis was done.

Statistical analysis: Descriptive statistics was used for the analysis. Chi square test was performed to correlate the three groups of blood sugar levels. All analysis was performed using statistical software (SPSS inc version 2.0, Chicago IL, USA) and $p$ value less than 0.05 was considered statistically significant.

\section{RESULTS AND DISCUSSION}

Out of a sample of eighty-six children included in the study, forty-four children were boys and forty-two children were girls (Figure 1). Twelve children had blood sugar level below the normal range. Seventy-three children had blood sugar level well within the normal range. Only one child had blood sugar level above the normal range (Figure 2). There was no statistically significant difference between the three groups. No significant correlation was found between random blood sugar level and early childhood caries in 1-6 years old children.

Diabetes is usually characterised by the deficiency in the level of insulin and dysfunctioning of the pancreatic beta cells. It has been proved in the past that diabetes poses risk for the cardiovascular and the renal system. Diabetes leads to disturbance in the glucose metabolism. This might lead to severe hyperglycemia and insulin deficiency. Certain disorders of the oral cavity have been associated with diabetes. Caries, gingival inflammation, periodontal inflammation, altered salivary function, taste dysfunction, oral mucosal diseases and infections such as lichen planus, aphthous stomatitis and candidiasis are associated with diabetes (Ferrannini, 1998; Siudikiene et al., 2005; Lamster, 2012; Abdelseed, 2021).

Figure 1: Bar chart representing the gender of the children included in the study. Blue represents boys included in the study and red represents girls included in the study. $X$ axis represents the gender of the children and $\mathrm{Y}$ axis represents the total number of children included in the study. Out of the total sample of 86 children $52 \%$ were boys and $48 \%$ were girls.

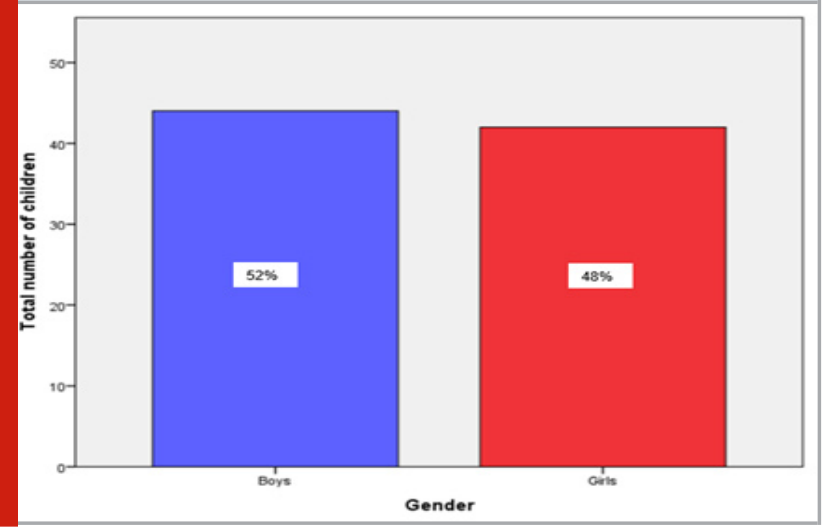

Figure 2: Bar chart representing level of blood sugar level in different age groups where blue represents below normal range, red represents normal range and green represents above normal range. $X$ axis represents the age of the child and $Y$ axis represents the number of children. Children in the age group of 3-4 years had normal and below normal range of random blood sugar level than that of children in the age group of 1-2 years and 5-6 years, however it is not statistically significant. Chi-square test, p-0.246 (p<0.05 which is not statistically significant).

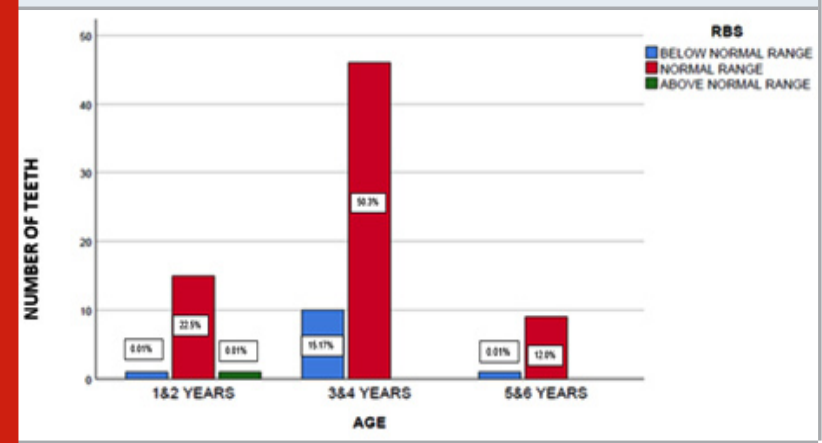

Assessment of blood sugar level in children is one of the ways to identify if the child is able to balance insulin from food and exercise. Abnormality in blood sugar levels produces symptoms associated with hyperglycemia as well as hypoglycemia. The relationship between diabetes and dental caries is complicated. Children suffering from type 1 diabetes are recommended a carbohydrate free diet along with restriction of cariogenic food. Children affected with type 2 diabetes tend to have a greater exposure to cariogenic food. Diet for children with diabetes includes intake of fat 
and protein and carbohydrates upto $50-60 \%$ of the daily calorie intake. Dental caries prevalence in diabetic children is due to interaction of genetic factors, oral microflora, diet and oral hygiene practices. Diabetic children tend to have increased prevalence of oral microflora like streptococcus mutans and lactobacilli. Salivary flow rate is reduced in children affected with diabetes (Ship, 2003; Panchal et al., 2019; Lakshmanan et al., 2020; Abdelseed, 2021)

This further leads to accumulation of microorganisms causing dental caries. Reduced salivary flow rate caused by hyperglycemia is characteristic mainly for periods of poor metabolic control of diabetes. During this period, glucose leakage into the oral cavity may occur, thereby facilitating the growth of aciduric and acidogenic bacteria and caries lesion development. A clear picture is not provided in previous literature regarding the relationship between dental caries and diabetes mellitus (Siudikiene et al., 2008; Sampaio et al., 2011; Panchal et al., 2019; Hanberger et al., 2021).

Jones et al reported an elevated risk of caries due to high blood sugar level. There is no literature correlating random blood sugar level with early childhood caries in children. Early childhood caries is defined as the presence of one or more decayed (non cavitated or cavitated lesions), missing (because of caries) or filled tooth surfaces in any primary tooth in a child aged 71 months or younger. Early childhood caries is often associated with certain factors like high sugar intake, lack of oral hygiene, lack of fluoride exposure and enamel defects. It is often associated with many oral health or systemic conditions (Jones et al., 1992; Christabel et al., 2015; Gurunathan and Shanmugaavel, 2016; Govindaraju and Gurunathan, 2017; Packiri et al., 2017; Govindaraju, 2017b; Subramanyam et al., 2018; Lakshmanan et al., 2020).

In the present study the children affected with early childhood caries were sent for a blood test where their random blood sugar level was evaluated. It was observed that most of the children (seventy-three children) affected with early childhood caries had their blood sugar level well within the normal range. Twelve children had blood sugar level below the normal range. These twelve children were further examined and their parents were questioned and a detailed history was taken. The parents were questioned about certain signs and symptoms like extreme hunger, tremors, rapid heart rate, weakness, drowsiness, confusion, headache and loss of consciousness. The parents of these children were asked to consult a child specialist immediately. One child had blood sugar level above the normal range. This child was detected with Type 1 diabetes mellitus in his first year of life. No relationship was established between blood sugar levels and early childhood caries in the present study. Reduction in salivary flow rate is usually present in children with high blood sugar levels. This further leads to caries. This has been proved by certain authors (Harrison and Bowen, 1987; Rivera Gómez et al., 2006; Jeevanandan and Govindaraju, 2018; Panchal et al., 2019; Mathew et al., 2020).
In the present study no child complained of dry mouth. Several studies have established a relationship of dental caries with blood sugar levels but no studies have been performed where blood sugar levels can be correlated with early childhood caries. In the present study random children were selected with early childhood caries. Specifically, children suffering from diabetes could have been included in the study to observe if they are affected with early childhood caries. Another limitation of the study was that the sample size included in the study was small. Further studies can be performed with a larger sample size and a more restricted inclusion criteria can be considered to establish a correlation between early childhood caries and blood sugar level. Our institution is passionate about high quality evidence based research and has excelled in various fields (Pc et al., 2018; Ramesh et al., 2018; Ezhilarasan et al., 2019; Ramadurai et al., 2019; Sridharan et al., 2019; Priyadharsini, 2019; Mathew et al., 2020).

\section{CONCLUSION}

In the present study it was proved that there was no significant correlation between blood sugar and dental caries in children between the age group of 1-6 years. It is recommended that in future more research should be performed with a larger sample size in order to establish better clarification with respect to the topic.

\section{REFERENCES}

Abdelseed, N.A.H., (2021). Glycemic Control and Knowledge among Children and Adolescents with Type 1 Diabetes Mellitus: A Cross-sectional Study. Journal of Scientific Research in Medical and Biological Sciences, 2(1), pp.1-9.

Association, A. D. and American Diabetes Association (2011). Diagnosis and Classification of Diabetes Mellitus. Diabetes Care, pp. S62-S69. doi: 10.2337/dc11-s062.

Christabel, S. L. and Linda Christabel, S. (2015). Prevalence of Type of Frenal Attachment and Morphology of Frenum in Children, Chennai, Tamil Nadu. World Journal of Dentistry, pp. 203-207. doi: 10.5005/jpjournals-10015-1343.

Ekoé, J.-M. and Zimmet, P. (2012). Diabetes Mellitus: Diagnosis and Classification. The Epidemiology of Diabetes Mellitus, pp. 11-29. doi: 10.1002/0470846429. ch3.

Ezhilarasan, D., Apoorva, V. S. and Ashok Vardhan, N. (2019). Syzygium cumini extract induced reactive oxygen species-mediated apoptosis in human oral squamous carcinoma cells. Journal of oral pathology \& medicine: official publication of the International Association of Oral Pathologists and the American Academy of Oral Pathology, 48(2), pp. 115-121.

Ferrannini, E. (1998). Insulin Resistance versus Insulin Deficiency in Non-Insulin-Dependent Diabetes Mellitus: Problems and Prospects. Endocrine Reviews, pp. 477-490. doi: 10.1210/edrv.19.4.0336.

Gheena, S. and Ezhilarasan, D. (2019). Syringic acid triggers reactive oxygen species-mediated cytotoxicity in 
HepG2 cells. Human \& experimental toxicology, 38(6), pp. 694-702.

Govindaraju, L. and Gurunathan, D. (2017). Effectiveness of Chewable Tooth Brush in Children-A Prospective Clinical Study. Journal of clinical and diagnostic research: JCDR, 11(3), pp. ZC31-ZC34.

Govindaraju, L., Jeevanandan, G. and Subramanian, E. (2017). Clinical Evaluation of Quality of Obturation and Instrumentation Time using Two Modified Rotary File Systems with Manual Instrumentation in Primary Teeth. Journal of clinical and diagnostic research: JCDR, 11(9), pp. ZC55-ZC58.

Govindaraju, L., Jeevanandan, G. and Subramanian, E. M. G. (2017a). Comparison of quality of obturation and instrumentation time using hand files and two rotary file systems in primary molars: A single-blinded randomized controlled trial. European journal of dentistry, 11(3), pp. 376-379.

Govindaraju, L., Jeevanandan, G. and Subramanian, E. M. G. (2017b). Knowledge and practice of rotary instrumentation in primary teeth among indian dentists: A questionnaire survey. Journal of International Oral Health, p. 45. doi: 10.4103/jioh.jioh_4_17.

Gurunathan, D. and Shanmugaavel, A. K. (2016). Dental neglect among children in Chennai. Journal of the Indian Society of Pedodontics and Preventive Dentistry, 34(4), pp. 364-369.

Harrison, R. and Bowen, W. H. (1987). Flow rate and organic constituents of whole saliva in insulin-dependent diabetic children and adolescents. Pediatric dentistry, 9(4), pp. 287-291.

Hanberger, L., Tallqvist, E., Richert, A., Olinder, A.L., Forsner, M., Mörelius, E. and Nilsson, S., (2021). NeedleRelated Pain, Affective Reactions, Fear, and Emotional Coping in Children and Adolescents With Type 1 Diabetes: A Cross-Sectional Study. Pain Management Nursing. Jeevanandan, G. (2017). Kedo-S Paediatric Rotary Files for Root Canal Preparation in Primary Teeth - Case Report. Journal of Clinical and Diagnostic Research. doi: 10.7860/ jcdr/2017/25856.9508.

Jeevanandan, G. and Govindaraju, L. (2018). Clinical comparison of Kedo-S paediatric rotary files vs manual instrumentation for root canal preparation in primary molars: a double blinded randomised clinical trial. European archives of paediatric dentistry: official journal of the European Academy of Paediatric Dentistry, 19(4), pp. 273-278.

Jones, R. B. et al. (1992). Oral health and oral health behaviour in a population of diabetic outpatient clinic attenders. Community Dentistry and Oral Epidemiology, pp. 204-207. doi: 10.1111/j.1600-0528. 1992.tb01717.x. Jose, J., Ajitha and Subbaiyan, H. (2020). Different treatment modalities followed by dental practitioners for Ellis class 2 fracture - A questionnaire-based survey. The open dentistry journal, 14(1), pp. 59-65.

Ke, Y. et al. (2019). Photosynthesized gold nanoparticles from Catharanthus roseus induces caspase-mediated apoptosis in cervical cancer cells (HeLa). Artificial cells, nanomedicine, and biotechnology, 47(1), pp. 19381946.

Krishnaswamy, H. et al. (2020). Investigation of air conditioning temperature variation by modifying the structure of passenger car using computational fluid dynamics. Thermal science, 24(1 Part B), pp. 495-498.

Lakshmanan, L. et al. (2020). Assessing the quality of obturation and instrumentation time using Kedo-S files, Reciprocating files and Hand K-files. Brazilian Dental Science. doi: 10.14295/bds.2020.v23i1.1822.

Lamster, I. B. (2012). Diabetes and oral health. What's their relationship? Diabetes self-management, 29(3), pp. 30, 32-4.

Lin, B. P. et al. (1999). Dental caries in older adults with diabetes mellitus. Special care in dentistry: official publication of the American Association of Hospital Dentists, the Academy of Dentistry for the Handicapped, and the American Society for Geriatric Dentistry, 19(1), pp. 8-14.

Mahesh, R., MM (2018). Fluoride, Fluoridated Toothpaste Efficacy And Its Safety In Children-Review'. International Journal of Pharmaceutical Research. doi, 10.

Malli Sureshbabu, N. et al. (2019). Concentrated Growth Factors as an Ingenious Biomaterial in Regeneration of Bony Defects after Periapical Surgery: A Report of Two Cases. Case reports in dentistry, 2019, p. 7046203.

Mathew, M. G. et al. (2020). Evaluation of adhesion of Streptococcus mutans, plaque accumulation on zirconia and stainless steel crowns, and surrounding gingival inflammation in primary. Clinical oral investigations. Available at: https://link.springer.com/article/10.1007/ s00784-020-03204-9.

Mehta, M. et al. (2019). Oligonucleotide therapy: An emerging focus area for drug delivery in chronic inflammatory respiratory diseases. Chemico-biological interactions, 308, pp. 206-215.

Mizia, S., Felińczak, A., Włodarek, D. and SyrkiewiczŚwitała, M., (2021). Evaluation of Eating Habits and Their Impact on Health among Adolescents and Young Adults: A Cross-Sectional Study. International Journal of Environmental Research and Public Health, 18(8), p.3996.

Moore, P. A. et al. (2001). Type 1 diabetes mellitus and oral health: assessment of coronal and root caries. Community dentistry and oral epidemiology, 29(3), pp. 183-194.

Muthukrishnan, S. et al. (2020). Support vector machine for modelling and simulation of heat exchangers. Thermal science, 24(1 Part B), pp. 499-503.

National Diabetes Education Program, (2001). PsycEXTRA Dataset. doi: 10.1037/e562842009-004.

Pachoński, M. et al. (2020). Dental caries and periodontal status in children with type 1 diabetes mellitus. Pediatric endocrinology, diabetes, and metabolism, 26(1), pp. 39-44.

Packiri, S., Gurunathan, D. and Selvarasu, K. (2017). Management of Paediatric Oral Ranula: A Systematic 
Review. Journal of clinical and diagnostic research: JCDR, 11(9), pp. ZE06-ZE09.

Panchal, V., Jeevanandan, G. and Subramanian, E. (2019). Comparison of instrumentation time and obturation quality between hand K-file, H-files, and rotary Kedo-S in root canal treatment of primary teeth: A randomized controlled trial. Journal of the Indian Society of Pedodontics and Preventive Dentistry, 37(1), pp. 75-79.

Pc, J., Marimuthu, T. and Devadoss, P. (2018). Prevalence and measurement of anterior loop of the mandibular canal using CBCT: A cross sectional study. Clinical implant dentistry and related research. Available at: https:// europepmc.org/article/med/29624863.

Priyadharsini V. J. (2019). In silico validation of the non-antibiotic drugs acetaminophen and ibuprofen as antibacterial agents against red complex pathogens. Journal of periodontology, 90(12), pp. 1441-1448.

Ramadurai, N. et al. (2019). Effectiveness of $2 \%$ Articaine as an anesthetic agent in children: randomized controlled trial. Clinical oral investigations, 23(9), pp. 3543-3550.

Ramesh, A. et al. (2018). Comparative estimation of sulfiredoxin levels between chronic periodontitis and healthy patients - A case-control study. Journal of periodontology, 89(10), pp. 1241-1248.

Ravikumar, D., Jeevanandan, G. and Subramanian, E. M. G. (2017). Evaluation of knowledge among general dentists in treatment of traumatic injuries in primary teeth: A cross-sectional questionnaire study. European journal of dentistry, 11(2), pp. 232-237.

Rivera Gómez, B. et al. (2006). The relationship between the levels of salivary cortisol and the presence of xerostomia in menopausal women. A preliminary study. Medicina oral, patologia oral y cirugia bucal, 11(5), pp. E407-12.

Sampaio, N., Mello, S. and Alves, C. (2011). Dental caries-associated risk factors and type 1 diabetes mellitus. Pediatric endocrinology, diabetes, and metabolism, 17(3), pp. 152-157.

Samuel, M. S. et al. (2019). Efficient removal of Chromium (VI) from aqueous solution using chitosan grafted graphene oxide (CS-GO) nanocomposite. International journal of biological macromolecules, 121, pp. 285-292. Samuel, S. R., Acharya, S. and Rao, J. C. (2020). School Interventions-based Prevention of Early-Childhood Caries among 3-5-year-old children from very low socioeconomic status: Two-year randomized trial. Journal of public health dentistry, 80(1), pp. 51-60.

Sathish, T. and Karthick, S. (2020). Wear behaviour analysis on aluminium alloy 7050 with reinforced $\mathrm{SiC}$ through taguchi approach. Journal of Japan Research Institute for Advanced Copper-Base Materials and Technologies, 9(3), pp. 3481-3487.

Sharma, P. et al. (2019). Emerging trends in the novel drug delivery approaches for the treatment of lung cancer. Chemico-biological interactions, 309, p. 108720.

Ship, J. A. (2003). Diabetes and oral health: an overview. Journal of the American Dental Association, 134 Spec No, p. $4 \mathrm{~S}-10 \mathrm{~S}$.

Siudikiene, J. et al. (2008). Dental Caries Increments and Related Factors in Children with Type 1 Diabetes Mellitus. Caries Research, pp. 354-362. doi: 10.1159/000151582. Siudikiene, J., Maciulskiene, V. and Nedzelskiene, I. (2005). Dietary and oral hygiene habits in children with type I diabetes mellitus related to dental caries. Stomatologija / issued by public institution 'Odontologijos studija', 7(2), pp. 58-62.

Somasundaram, S. et al. (2015). Fluoride Content of Bottled Drinking Water in Chennai, Tamilnadu. Journal of clinical and diagnostic research: JCDR, 9(10), pp. ZC32-4.

Sridharan, G. et al. (2019). Evaluation of salivary metabolomics in oral leukoplakia and oral squamous cell carcinoma. Journal of oral pathology \& medicine: official publication of the International Association of Oral Pathologists and the American Academy of Oral Pathology, 48(4), pp. 299-306.

Subramanyam, D. et al. (2018). Comparative evaluation of salivary malondialdehyde levels as a marker of lipid peroxidation in early childhood caries. European journal of dentistry, 12(1), pp. 67-70.

Twetman, S. et al. (2002). Caries Incidence in Young Type 1 Diabetes mellitus Patients in Relation to Metabolic Control and Caries-Associated Risk Factors. Caries Research, pp. 31-35. doi: 10.1159/000057587.

Varghese, S. S., Ramesh, A. and Veeraiyan, D. N. (2019). Blended Module-Based Teaching in Biostatistics and Research Methodology: A Retrospective Study with Postgraduate Dental Students. Journal of dental education, 83(4), pp. 445-450.

Venu, H., Raju, V. D. and Subramani, L. (2019). Combined effect of influence of nano additives, combustion chamber geometry and injection timing in a DI diesel engine fuelled with ternary (diesel-biodiesel-ethanol) blends. Energy, 174, pp. 386-406.

Venu, H., Subramani, L. and Raju, V. D. (2019). Emission reduction in a DI diesel engine using exhaust gas recirculation (EGR) of palm biodiesel blended with $\mathrm{TiO} 2$ nano additives. Renewable Energy, 140, pp. 245-263.

Vignesh, R. et al. (2019). Management of Complicated Crown-Root Fracture by Extra-Oral Fragment Reattachment and Intentional Reimplantation with 2 Years Review. Contemporary clinical dentistry, 10(2), pp. 397-401.

Vijayakumar Jain, S. et al. (2019). Evaluation of ThreeDimensional Changes in Pharyngeal Airway Following Isolated Lefort One Osteotomy for the Correction of Vertical Maxillary Excess: A Prospective Study. Journal of maxillofacial and oral surgery, 18(1), pp. 139-146.

Wegner, H. (1971). Dental caries in young diabetics. Caries research, 5(2), pp. 188-192. 